\title{
Chronic Administration of 13-Cis-Retinoic Acid Increases Depression-Related Behavior in Mice
}

\author{
Kally C O'Reilly', Jason Shumake², F Gonzalez-Lima ${ }^{2}$, Michelle A Lane ${ }^{*, 1,3,5}$ and Sarah J Bailey ${ }^{4,5}$ \\ 'Institute of Cellular and Molecular Biology, The University of Texas at Austin, Austin, TX, USA; '2Department of Psychology, The University \\ of Texas at Austin, Austin, TX, USA; ${ }^{3}$ Division of Nutritional Sciences, Department of Human Ecology, The University of Texas at Austin, Austin, \\ TX, USA; ${ }^{4}$ Department of Pharmacy and Pharmacology, University of Bath, Bath, UK
}

\begin{abstract}
Retinoid signaling plays a well-established role in neuronal differentiation, neurite outgrowth, and the patterning of the anteroposterior axis of the developing neural tube. However, there is increasing evidence that nutritional vitamin A status and retinoid signaling play an important role in the function of the adult brain. 13-Cis-retinoic acid (I3-cis-RA) (isotretinoin or Accutane), a synthetic retinoid that is an effective oral treatment for severe nodular acne, has been linked with depression and suicide in patients. The purpose of this study was to test the hypothesis that chronic administration of I3-cis-RA would lead to depression-related behaviors in mice. Young, adult male mice received 13 -cis-RA $(\mathrm{l} \mathrm{mg} / \mathrm{kg})$ by daily intraperitoneal injection for 6 weeks. This treatment paradigm produced plasma levels of 13 -cis-RA that are comparable to those reported in human patients taking Accutane. In both the forced swim test and the tail suspension test, we found that I3-cis-RA-treated mice spent significantly more time immobile compared to vehicle-treated controls. In the open field test, there was no change in anxiety-related behavior in 13-cis-RA-treated mice. Furthermore, chronic administration of 13-cis-RA did not impair locomotion in either the open field or the rotarod test. Taken together, these results suggest that administration of I3-cis-RA increases depression-related behaviors in mice.

Neuropsychopharmacology (2006) 31, 1919-1927. doi: I0.1038/sj.npp. 1300998; published online 4 January 2006
\end{abstract}

Keywords: isotretinoin; Accutane; forced swim test; tail suspension test; depression; mice

\section{INTRODUCTION}

Retinoids, including vitamin A and its derivatives, have long been studied for their role in embryonic development because excess retinoids induce neural tube defects. Emerging evidence now indicates that retinoid signaling pathways also affect the functioning of the adult brain (for a review, see Mey and McCaffery, 2004; Lane and Bailey, 2005). Retinoids exert their effects by binding to nuclear retinoic acid receptors (RAR), which function as heterodimers with retinoid $\mathrm{X}$ receptors (RXR) (for a review, see Lane and Bailey, 2005). The RAR/RXR heterodimer regulates gene transcription by binding to specific DNA sequences termed retinoic acid response elements (RARE) found in the promoter regions of retinoid responsive genes.

*Correspondence: Dr MA Lane, Division of Nutritional Sciences, Department of Human Ecology, Gearing Hall Room II5, Mail Stop A2700, The University of Texas at Austin, Austin, TX 78712, USA, Tel: + | 512232 9410, Fax: + | 512 47| 5844,

E-mail: mlane@mail.utexas.edu

${ }^{5}$ These authors contributed equally to this work.

Received 8 August 2005; revised 24 October 2005; accepted 27 October 2005

Online publication: I November 2005 at http://www.acnp.org/citations/ Npp I 10 I05050496/default.pdf
The adult brain expresses many of the components of the retinoid signaling machinery necessary to control retinoid metabolism and transport. For example, retinal dehydrogenases, which synthesize active all-trans-retinoic acid from dietary vitamin A (McCaffery and Drager, 1994; Thompson Haskell et al, 2002; Wagner et al, 2002), cellular retinoid binding proteins (Zetterstrom et al, 1994, 1999), and RAR $\alpha$ and RAR $\beta$ (Krezel et al, 1999; Zetterstrom et al, 1999) are all expressed in the adult brain. Given the role of retinoids in neuronal differentiation, it is not surprising that a large number of neuronal genes have been shown to be retinoidresponsive (for a review, see Lane and Bailey, 2005). However, only a small subset of neuronal genes have identified, functional RARE in their promoter regions: dopamine D2 receptor (Valdenaire et al, 1994; Samad et al, 1997; Valdenaire et al, 1998), neurogranin (RC3) (Iniguez et al, 1994; Husson et al, 2004), gonadotrophin-releasing hormone (Cho et al, 2001a,b), and oxytocin (Richard and Zingg, 1991). Consequently, retinoid-responsive gene transcription in the central nervous system could have a significant impact on the function of the adult brain. Indeed, such a role for retinoids has been demonstrated in learning and memory behaviors (Chiang et al, 1998; Etchamendy et al, 2001; Cocco et al, 2002; Etchamendy et al, 2003; Crandall et al, 2004). 
13-cis-RA (or isotretinoin) is a synthetic retinoid and the active ingredient in Accutane, a widely prescribed oral acne medication (Shalita et al, 1988). Originally intended to treat severe nodular acne that was unresponsive to conventional treatments, the use of 13-cis-RA for milder forms of acne is increasing (Hull and D'Arcy, 2003). Since the mid-1980s, reports in the literature suggest a relationship between 13cis-RA use and the onset of psychological symptoms including depression, suicidal ideation, and psychosis (Hazen et al, 1983; Bigby and Stern, 1988; Scheinman et al, 1990; Byrne and Hnatko, 1995; Wysowski et al, 2001; $\mathrm{Ng}$ and Schweitzer, 2003; O'Connell et al, 2003; Barak et al, 2005). However, there are also studies suggesting that there is no evidence of such a link (Jick et al, 2000; Jacobs et al, 2001; Ferahbas et al, 2004; Chai et al, 2005). One recent study used positron emission tomography to examine brain function in patients with treatment-resistant acne (Bremner et al, 2005). In patients treated with 13-cis-RA, but not antibiotic, there was a significant decrease in orbitofrontal cortical metabolism. However, there was no difference in depressive symptoms between the two treatment groups (Bremner et al, 2005).

Patients with disfiguring acne exhibit problems with selfesteem, self-image, depression, and anger (Koo, 1995) that could confound depressive symptoms arising due to 13-cisRA treatment. The use of an animal model allows for the separation of the effects of acne on self-image and mood from those of 13-cis-RA itself on depression-related behavior. However, there are only a few reports concerning the effects of 13-cis-RA in animal models of depressionrelated behavior. Crandall et al (2004) have shown that long-term administration of 13-cis RA in adult mice suppresses hippocampal neurogenesis (Crandall et al, 2004). Deficits in adult neurogenesis in the hippocampus have been proposed to underlie depression (Jacobs et al, 2000 ), especially as they are sensitive to reversal by antidepressant administration (Malberg and Schechter, 2005). Crandall et al (2004) reported impairments in spatial learning but did not examine depression-related behaviors in mice. More recently, Ferguson et al (2005) reported that high doses of 13-cis-RA do not affect depression-related behavior in adult rats. The objective of the present study was to determine whether 13-cis-RA, administered in a dose identical to that prescribed to human patients, could alter depression- or anxiety-related behaviors in young adult mice. Here, we report for the first time that chronic administration of 13-cis-RA to mice significantly increases the time spent immobile in both the forced swim and the tail suspension tests. Such increases in immobility in these behavioral despair paradigms are consistent with increased depression-related behavior.

\section{METHODS}

\section{Animals}

Young, adult male DBA/2J (Jackson Laboratories, Bar Harbor, ME) mice were used in this study. Animals were 3 weeks old at arrival and 4 weeks old at the start of treatment. Mice were group housed four per cage and maintained under a 12:12 h light/dark cycle. Food and water were provided ad libitum. All procedures and tests performed on animals were approved by the University of Texas IACUC, protocol number 04100403, and according to the National Institutes of Health Guide for the Care and Use of Laboratory Animals.

\section{Treatment}

Animals were allowed to adapt to the University of Texas animal facility for 1 week prior to initial injection. Animals were handled during this week to reduce the stress of receiving daily injections. A $2 \mathrm{mg} / \mathrm{ml}$ stock solution of 13 cis-RA in DMSO was stored for up to 1 week at $-20^{\circ} \mathrm{C}$. The stability of 13-cis-RA after 1 week of storage was confirmed by comparing the absorbance at $354 \mathrm{~nm}$ to that of a freshly prepared sample (Crandall et al, 2004). Sterile injection samples were prepared in the dark. Injections were performed $1 \mathrm{~h}$ prior to the start of the dark cycle in the same room where the animals were housed and one person performed all injections. Treated animals $(n=12)$ received daily intraperitoneal (i.p.) injections of $1 \mathrm{mg} / \mathrm{kg} /$ day $13-c i s-$ RA (Sigma, St Louis, MO), dissolved in sterile 50\% DMSO/ $50 \%$ saline $(0.9 \%)$ to a final volume of $200 \mu \mathrm{l}$. Control animals $(n=12)$ were administered $200 \mu \mathrm{l}$ of vehicle $(50 \%$ DMSO/50\% saline), i.p., daily. Animals were injected for 6 weeks prior to behavioral testing. Daily injections continued throughout the testing period and all animals received injections $14 \mathrm{~h}$ before any behavioral testing to eliminate any acute effects of injection. Only one behavioral test was performed each day and approximately $24 \mathrm{~h}$ elapsed between tests. The behavioral experiments were conducted in the following order: tail suspension test, forced swim test, open field test, and rotarod test.

\section{3-Cis-RA Plasma Level Determination}

After behavioral testing, blood samples were collected from treated animals immediately post mortem. 13-Cis-RA was administered to the mice approximately $16 \mathrm{~h}$ before killing. To prevent retinoid degradation, all steps were performed in the dark. The blood was allowed to coagulate for $30 \mathrm{~min}$ and then centrifuged at $1000 \mathrm{~g}$ for $20 \mathrm{~min}$. The plasma was then removed and stored at $-80^{\circ} \mathrm{C}$ until the retinoid extraction was performed. Samples were extracted as described (Lane et al, 1999). In total, 0.7 volumes of acetonitrile : butanol $(1: 1)$ solution was added to the sample and vortexed for $45 \mathrm{~s}$, then 0.6 volumes of saturated $\mathrm{K}_{2} \mathrm{HPO}_{4}$ was added and vortexed for $10 \mathrm{~s}$. The samples were then centrifuged at $13000 \mathrm{~g}$ for $10 \mathrm{~min}$. The upper layer was removed and the sample volume brought up to $100 \mu \mathrm{l}$ with $100 \%$ acetonitrile. The absorbance of the samples was determined at $354 \mathrm{~nm}$ and 13-cis-RA concentration was determined by comparison to a standard curve. For the standard curve, a known amount of 13-cis-RA was added to plasma from mice not treated with Accutane and extracted as described above. All concentration values were corrected for initial and extracted sample volumes.

\section{Tail Suspension Test}

To perform the tail suspension test, animals were suspended by the tail on a horizontal beam $33 \mathrm{~cm}$ high. Mice were taped to the bar using adhesive tape placed 
approximately $1 \mathrm{~cm}$ from the tip of the tail. A 6-min test period was used and videotaped for subsequent analysis The animals engaged in several escape-related behaviors interspersed with periods of immobility. The duration of immobility was measured in seconds. The mice were tested in a randomized, double-blinded manner.

\section{Porsolt Forced Swim Test}

The forced swim test is a pharmacologically validated model of depression-related behavior in mice (Lucki et al, 2001). Mice were placed in a Plexiglas, cylindrical tank, $20 \times 51 \mathrm{~cm}$, filled to a depth of $35 \mathrm{~cm}$ with room temperature water $\left(25 \pm 0.5^{\circ} \mathrm{C}\right)$ for a total of $6 \mathrm{~min}$ and the test was videotaped for subsequent analysis. Mice were scored for each of three behaviors: swimming, climbing, and immobility. Immobility was defined as the absence of escape-related behavior, such as swimming, climbing, or rearing. Swimming behavior was assigned when the animal was moving around the container with all the paws, while climbing behavior was assigned when the animal became vertical and clawed at the cylinder walls with its forepaws. The duration of each of these behaviors was measured in seconds over a 6-min period. The mice were tested in a randomized, doubleblinded manner.

\section{Open Field Test}

The open field test was used to evaluate anxiety-related behaviors (Mathis et al, 1994, Prut and Belzung, 2003). Animals were placed in a $16 \times 16 \mathrm{~cm}$ open field apparatus (Med Associates, St Albans, VT). Ambulatory and stereotypic activity was measured by infrared motion detectors spaced $2.5 \mathrm{~cm}$ apart. Rearing and jumping activity was measured by another set of infrared motion detectors $4.6 \mathrm{~cm}$ above the floor. The animal activity was monitored by Activity Monitor, version 5.10 (Med Associates, St Albans, VT) over the course of $5 \mathrm{~min}$. The ambulatory time was determined in seconds for each minute spent in the open field as were the total ambulatory, vertical, and stereotypic times. The time spent and distance traveled in the center (38\% of the total field area) and the number of entries into the center of the field were also calculated. Motor function was also assessed by considering the total distance traveled in the open field during the 5-min observation period.

\section{Rotarod Test}

In order to determine the effect of retinoids on motor coordination, the rotarod test was performed. The rotarod test consisted of placing the animal on a rotating rod, $4 \mathrm{~cm}$ in diameter, $35 \mathrm{~cm}$ high (Columbia Instruments, Columbus, $\mathrm{OH})$. Low rotation speeds were chosen for this test, since DBA/2J mice perform this task relatively poorly at higher speeds (Brooks et al, 2004). The animals were first placed on a rod rotating at $5 \mathrm{rpm}$ for $2 \mathrm{~min}$ to acclimate to this novel motor task. Each time an animal fell from the rod during this time period, the animal was placed back onto the rod. After the 2-min acclimation period, the animal was allowed to rest for $1 \mathrm{~min}$ and then placed back on the rod rotating at $5 \mathrm{rpm}$. The latency to fall was then measured in seconds. The animal was then placed on the rod for a second trial at a rotation speed of $10 \mathrm{rpm}$. The latency to fall was again measured in seconds. In all trials, if the mouse did not fall from the rod, it was removed from the rod after $2 \mathrm{~min}$.

\section{Behavioral Evaluation and Statistics}

All behavioral tests were double-blinded and all were scored prior to decoding any of the tests. Immobility data from the last $4 \mathrm{~min}$ of both the tail suspension and forced swim tests were analyzed with a $2 \times 2 \times 4$ (Group $\times$ Test $\times$ Minute) repeated measures ANOVA, with the two tests and $4 \mathrm{~min}$ serving as repeated measures. We analyzed the two immobility tests in this way because they both examine the same construct (depressive behavior) using the same units of measurement (seconds of immobility). This omnibus approach has been successfully applied to other behavioral measures meeting these criteria (Shumake et al, 2005). Only the last $4 \mathrm{~min}$ of each test were used in the analysis because of widespread zero values during the first 2 min of each test. The open-field and rotorod data were analyzed by two-tailed $t$-tests. Values reported are mean \pm SEM of $n=12$ observations unless otherwise indicated.

\section{RESULTS}

\section{Confirmation of 13-Cis-RA Plasma Levels in Treated Mice}

The human dose of 13-cis-RA used to treat acne ranges from 0.5 to $2 \mathrm{mg} / \mathrm{kg} /$ day. The mice used in this study received an amount of 13-cis-RA within this range and identical to the amount administered to mice in the study by Crandall et al (2004). The plasma level of 13-cis-RA in six mice chronically treated with 13 -cis-RA was $1.5 \pm 0.4 \mu \mathrm{g} / \mathrm{ml}$. This value is higher than that previously observed by Crandall et al (2004), potentially due to the use of different retinoid extraction techniques. However, the plasma levels obtained in the present study are approximately twice that displayed by humans administered $0.5 \mathrm{mg} / \mathrm{kg} /$ day of 13 -cis-RA, onehalf the dose used in the present study. Plasma 13-cis-RA concentrations in these patients reached $0.74 \mu \mathrm{g} / \mathrm{ml}$ (Kerr et al, 1982). In addition, the plasma concentration obtained in the present study is similar to that reported in the Accutane capsules package insert were the peak plasma concentration of 13-cis-RA in healthy patients aged 12-15 years receiving multiple oral doses of 13-cis-RA for the treatment of severe acne ranged from 0.37 to $1.09 \mu \mathrm{g} / \mathrm{ml}$. Therefore, administration of $1 \mathrm{mg} / \mathrm{kg} /$ day of 13 -cis-RA to young, adult male mice results in plasma 13-cis-RA levels similar to those observed in human patients.

\section{3-Cis-RA Treatment had no Effect on Weight Gain}

Weight gain over the 6 weeks of injections was followed to ensure that the animals were not showing overt signs of distress or discomfort. Weekly weighing of the mice showed that overall weight gain across the experiment was normal and that there was no difference in body weight between the 13-cis-RA-treated group and the control group. At the start of injections, the 13-cis-RA-treated group weighed $15.5 \pm 0.4 \mathrm{~g}$ and the control group weighed $15.1 \pm 0.3 \mathrm{~g}$. At 
the beginning of the behavioral testing, the treatment group weighed $23.8 \pm 0.5 \mathrm{~g}$ and the control group weighed $23.1 \pm 0.5 \mathrm{~g}$. The behavioral tests had no effect on the weight of the animals. Daily monitoring confirmed that the animals were not showing any signs of distress as a result of the repeated injections, which were given on alternating sides of the abdominal cavity. The injections were verified to be i.p. and not subcutaneous by feeling the skin on the underside of the animals daily for bubbles or scar tissue.

\section{Chronic Administration of 13-Cis-RA Increases Immobility in the Tail Suspension and Forced Swim Tests}

The effect of chronic administration of 13-cis-RA on young adult mouse behavior in the tail suspension ( $a$ and $b$ ) and forced swim (c and d) tests is shown in Figure 1. Both tests are pharmacologically validated models of behavioral despair in which the time spent immobile decreases with antidepressant treatment (Cryan et al, 2005; Lucki, 1997). The $2 \times 2 \times 4$ (Group $\times$ Test $\times$ Minute) repeated measures ANOVA of the immobility data showed no significant interactions and no significant effect of test, supporting the validity of analyzing the two tests in this way. There was a significant main effect of group, $\mathrm{F}(1,21)=4.8, p=0.039$, with 13-cis-RA-treated mice showing significantly more immobility than vehicle controls. The estimated marginal means and standard errors for the two groups were $19 \pm 2.1 \mathrm{~s}$ of immobility per minute for the 13-cis-RAtreated group and $12 \pm 2.0 \mathrm{~s}$ of immobility per minute for the vehicle controls. The increase in immobility due to 13cis-RA treatment observed in the forced swim test appears to be due to a decrease in swimming behavior (Figure 1c). There was no difference between the groups for the amount of time the animals spent engaged in climbing activity. These data show that chronic 13-cis-RA administration increases immobility in both the tail suspension and forced swim tests, which is indicative of increased depressionrelated behavior.

\section{Chronic Administration of 13-Cis-RA has no Effect on Anxiety-Related and Motor Behavior in the Open Field Test}

Approximately $25-50 \%$ of depressed youth also exhibit anxiety. Selective serotonin reuptake inhibitors have been used successfully to treat both depression and anxiety, potentially indicating a common etiology (for a review, see
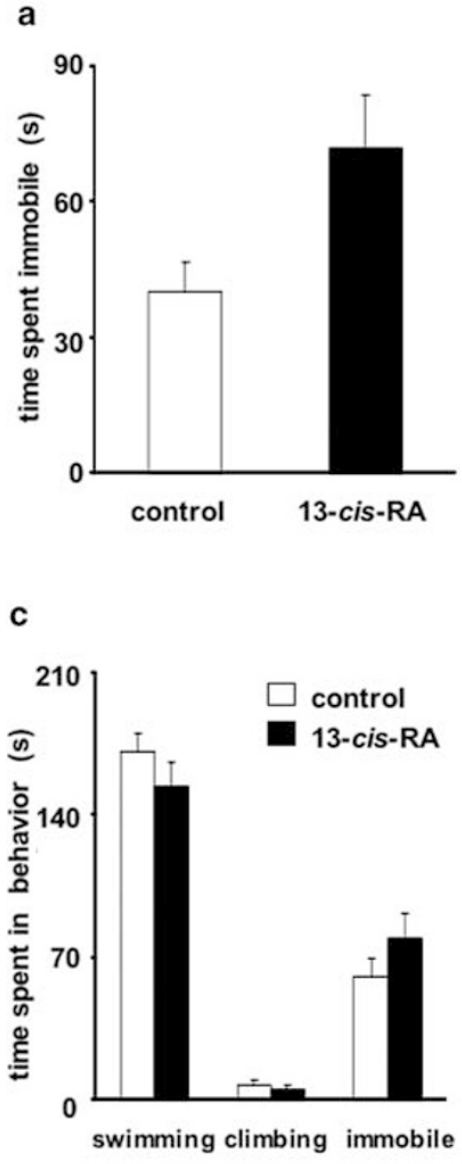

b

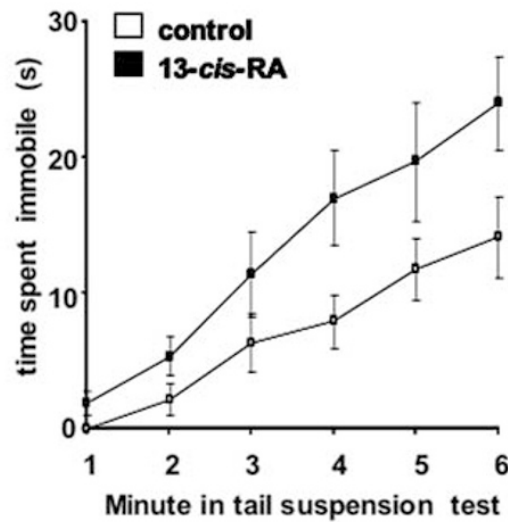

d

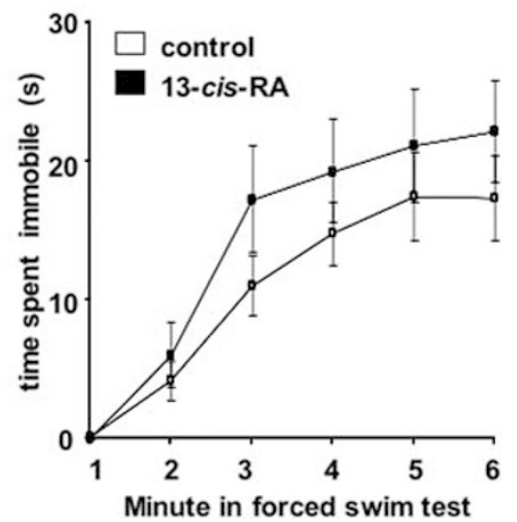

Figure I 13-Cis-RA increases immobility in the tail suspension and forced swim tests. Total time spent immobile in the tail suspension (a) and forced swim (c) tests are expressed as the mean \pm SEM for the last 4 min of the observation period. The development of immobility during the tail suspension (b) and forced swim (d) tests are shown as mean \pm SEM seconds per each minute of the 6-min observation period. Overall, immobility time from both tests (as assessed by repeated measures ANOVA) showed a significant main effect of group, $F(I, 2 I)=4.8, p=0.039$, with I3-cis-RA-treated mice showing significantly more immobility than vehicle controls. $n=11$, I3-cis-RA-treated mice and $n=12$, control mice. 
Axelson and Birmaher, 2001). Also, in mice, anxiety may be one factor that contributes to susceptibility to depressionrelated behaviors (Ducottet and Belzung, 2005). The open field test is an anxiety-related behavioral paradigm that is sensitive to anxiolytic drugs (Mathis et al, 1994; Prut and Belzung, 2003). An animal exhibiting anxiety-related behavior will spend less time in the center of the open field. There was no difference between the 13-cis-RA-treated group and the control group in the number of entries into the inner zone of the field between the two groups $(p=0.61)$ (Figure 2a). 13-Cis-RA-treated mice made $21 \pm 4$ entries into the inner field and control animals made $24 \pm 2$ entries.

Retinoid signaling affects locomotion. For example, $\operatorname{RAR} \beta-\operatorname{RXR} \beta, \operatorname{RAR} \beta-\operatorname{RXR} \gamma$, and $\operatorname{RXR} \beta-\operatorname{RXR} \gamma$ double null mutant mice (but not the corresponding single mutants) exhibit reduced forward locomotion and rearing frequency in the open field test (Krezel et al, 1998). Also, retinoic acidmediated effects have been implicated in Parkinson's (Eichele, 1997) and Huntington's disease (Luthi-Carter et al., 2000) (for a review, see Lane and Bailey, 2005). Therefore, to assure that the effects of 13-cis-RA on behavior in the tail suspension and forced swim tests were due to a specific increase in despair-related behavior and not to an overall decrease in locomotion or coordination, we conducted the open field and rotarod tests, respectively. There was no difference in total ambulatory time $(p=0.68)$ or the ambulatory time in the inner zone of the field $(p=0.68)$ between the two groups (Figure $2 \mathrm{~b})$. The total ambulatory time of mice treated with 13 -cis-RA was $55 \pm 3 \mathrm{~s}$ vs $57 \pm 2$ s for the control mice. The ambulatory time for the 13-cis-RA-treated mice in the inner zone of the field was $7 \pm 1 \mathrm{~s}$, while control mice had $8 \pm 1 \mathrm{~s}$ of ambulatory time in the inner zone of the open field. Additionally, there was no difference in the ambulatory distance traveled over the entire field $(p=0.78)$ or the inner zone of the field $(p=0.93)$ (Figure 2c). 13-Cis-RA-treated mice traveled $1426 \pm 98 \mathrm{~cm}$ while control mice traveled $1451 \pm 57 \mathrm{~cm}$ over the entire field. 13-Cis-RA-treated mice traveled $211 \pm 30 \mathrm{~cm}$ in the inner zone and the control mice traveled $216 \pm 19 \mathrm{~cm}$. As 13-cis-RA treatment did not alter the number of entries into, or the total distance traveled in, the center zone of the open field, it is unlikely that 13-cis-RA has an effect on anxiety-related behavior. The lack of a difference between groups with respect to total distance traveled or total ambulatory time indicates that 13-cis-RA has no effect on overall locomotion compared with vehicle-treated controls.

\section{Chronic 13-Cis-RA Administration Increases Motor Coordination on the Rotarod}

There was no impairment of motor coordination in mice treated with 13-cis-RA (Figure 3). There was a trend for mice treated with 13-cis-RA to remain on the rotating rod longer than control mice when tested at a rotational speed of $5 \mathrm{rpm}(p=0.07)$. Mice administered 13-cis-RA were able to stay on the rod for $105 \pm 10 \mathrm{~s}$, whereas control mice were only able to remain on the rod for $75 \pm 13 \mathrm{~s}$. However, when tested at $10 \mathrm{rpm}$, there was no difference between the latency to fall time for the treated and control mice $(p=0.91)$. Retinoids have been implicated in the regulation of locomotion because $\operatorname{RAR} \beta-\operatorname{RXR} \beta, \operatorname{RAR} \beta-\operatorname{RXR} \gamma$, and $\operatorname{RXR} \beta-\operatorname{RXR} \gamma$ double null mutant mice were shown to have
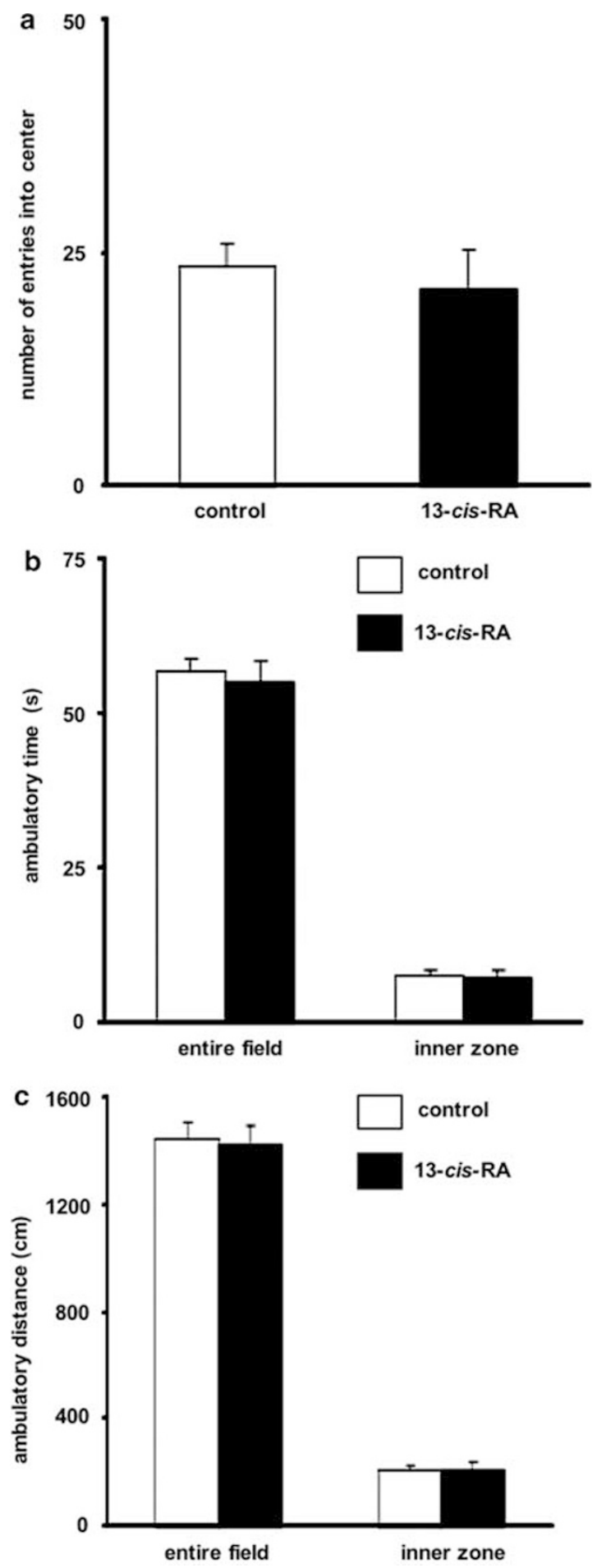

Figure 2 |3-Cis-RA does not affect performance in the open field test. The number of entries into the center (a), the total ambulatory time (b), and the total ambulatory distance (c) measured during a 5-min observation period in the open field test. In each case, there was no difference between I3-cis-RA-treated mice and vehicle-treated controls. Values are mean \pm SEM with $n=12$ for each group.

locomotor deficits (Krezel et al, 1998). In contrast, chronic 13-cis-RA treatment tends to improve motor coordination at low rotational speeds in the rotarod test without an effect on total locomotion (Figure 2). 


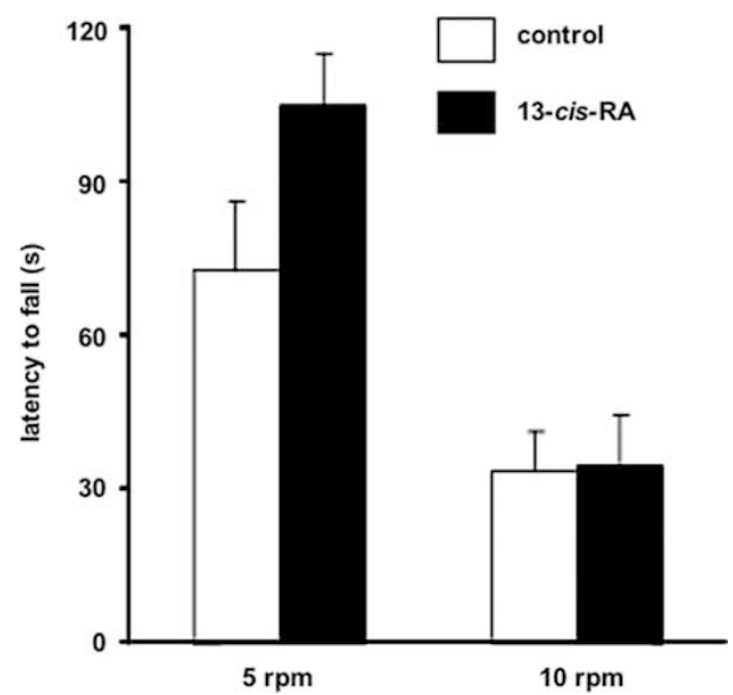

Figure 3 |3-Cis-RA does not impair motor performance in the rotarod test. The mean latency to fall from a rod rotating at 5 or at $10 \mathrm{rpm}$ is shown during a 2-min test period. The 13-cis-RA-treated mice tended to remain on the rotarod longer at $5 \mathrm{rpm}$. Treatment had no effect on rotarod performance at $10 \mathrm{rpm}$. Values are mean \pm SEM with $n=12$ for each group.

\section{DISCUSSION}

Here we demonstrate that chronic administration of 13-cisRA to young adult male mice increased the time spent immobile in both the tail suspension and forced swim tests. In the open field test, there was no evidence of a change in anxiety-related behavior. Furthermore, there was no impairment of locomotion or motor coordination in 13-cisRA-treated animals. Taken together, these data indicate that the increased immobility in behavioral despair paradigms is not due to an effect on motor systems, but results from increased depression-related behavior. Increased immobility in the forced swim test has been exhibited by mice and rats in situations that increase vulnerability to depression such as estradiol deficiency due to aromatase knockout (Dalla et al, 2004), stress due to food restriction (Alcaro et al, 2002), magnesium depletion (Singewald et al, 2004), and choline administration (Carlezon et al, 2002). The behavior of the animals in the tail suspension test was not assessed in these studies. However, increased immobility in both the forced swim and tail suspension tests does occur in mice and rats due to the pro-depressant effects of withdrawal from chronic amphetamine administration (Cryan et al, 2003), centrally administered urotensin-II (Do-Rego et al, 2005), and interleukin-1 and endotoxin injection (Dunn and Swiergiel, 2005). Interestingly, in the forced swim test, antidepressants that target the serotonergic system increase swimming behavior, thereby decreasing immobility (Detke et al, 1995). On the other hand, antidepressants that target noradrenergic systems increase climbing behavior. In our experiments, 13-cis-RA treatment leads to an increased immobility with a concomitant decrease in swimming behavior, without an effect on climbing behavior. This may indicate that chronic 13-cisRA administration disrupts serotonergic systems, leading to increased depression-related behavior.
A recent study reported the effects of chronic 13-cis-RA administration on adult rats. In the forced swim test, Ferguson et al (2005) reported a marginally significant effect of 13-cis-RA treatment on immobility. However, in contrast to our observations, these authors observed less immobility following 13-cis-RA administration. This reduced immobility was observed for a successive 2 -day test in which the immobility for the second day was found to be decreased in all test groups. This analysis was performed by averaging the data across the two separate test days. The fact that immobility was decreased on the second test day is surprising because the forced swim test, when conducted on consecutive days, generally results in increased immobility each day regardless of treatment (Bhatnagar et al, 2004). In addition, Ferguson et al (2005) reported that there was no change in voluntary saccharin solution intake in treated rats, reflecting an absence of the depressive symptom anhedonia. The authors concluded that 13-cis-RA treatment did not severely affect depression-like behaviors in rats. There are three important differences between our study and that of Ferguson et al (2005): (1) age and species of test subjects, (2) method of dosing, and (3) dose of drug administered. The adolescent mice were used in our study because Accutane is administered primarily to human adolescents. Our mice are at an earlier stage of development than the adult rats used by Ferguson et al (2005); we began dosing between the time of cessation of weaning and the onset of sexual maturity. The dose of 13-cis-RA we administered was $1 \mathrm{mg} / \mathrm{kg}$ via i.p. injection in comparison to the much higher doses $(7.5$ and $22.5 \mathrm{mg} / \mathrm{kg}$ ) used by Ferguson et al (2005) administered by oral gavage. The dose we used is within the recommended range for treatment of patients $(0.5-2.0 \mathrm{mg} / \mathrm{kg} /$ day $)$ and we achieved serum levels in treated mice that were equivalent to those seen in patients. Repeated drug administration is a potential stressor and stress has been shown to influence depression-related behavior (Shumake and Gonzalez-Lima, 2003). Ferguson et al (2005) also examined behavior in the open field, and in one treatment group saw that 13-cis-RA-treated rats were significantly less active than same sex controls. This increase in freezing time in the open field increased with the duration of treatment even in control animals. One explanation for this is that all animals were exhibiting enhanced stress-responses that can manifest as increased freezing time in the open field test. It is therefore possible that Ferguson et al (2005) were not able to detect changes in depression-related behaviors in 13-cis-RA-treated animals because they were masked by elevated stress in all treatment groups.

Changes in adult behavior as a result of 13-cis-RA administration are perhaps not surprising given the evidence linking retinoid signaling to adult CNS function (Mey and McCaffery, 2004; Lane and Bailey, 2005). A large number of neuronal genes have been shown to be retinoidresponsive (for a review see Lane and Bailey, 2005), but it is not yet known whether 13-cis-RA can regulate gene transcription in the adult brain. 13-Cis-RA could be activating gene transcription by either isomerizing to alltrans-retinoic acid and binding to the RAR (Tsukada et al, 2000) or directly binding to the RAR itself (Idres et al, 2002). Although 13-cis-RA binds to the RAR with much lower affinity than all-trans-retinoic acid, once bound to the 
RAR, 13-cis-RA is very efficient at initiating transcription (Idres et al, 2002). Given that depression is a complex, multifactorial phenomenon involving dopaminergic, serotonergic, noradrenergic, and other transmitter pathways, altered regulation of a subset of target genes by 13-cis-RA could produce subtle changes in neuronal function that lead to enhanced depression-related behaviors. For example, a verified RARE has been found in the promoter region of the dopamine D2 receptor and all-trans-retinoic acid can upregulate dopamine D2 receptor expression (Samad et al, 1997). Increased dopamine D2 receptor abundance has been reported in patients with major depression (Klimek et al, 2002). Similarly, the 5-hydroxytryptamine $1 \mathrm{~A}$ receptor, which has a role in regulating the firing of serotonin neurons and is associated with depression-related personality traits (Strobel et al, 2003), has been shown to be upregulated in response to all-trans-retinoic acid treatment in neuronal cells (Charest et al, 1993). Altered regulation of either the D2 receptor or the 5-HT 1A receptor genes by 13cis-RA, as well as other neuronal genes, could provide a possible mechanism for the changes in depression-related behaviors seen in chronically treated mice.

An alternative mechanism by which 13-cis-RA could alter depression-related behaviors is by affecting adult neurogenesis. Apart from the well-documented effects of retinoids on neuronal differentiation during development (Maden, 2002), retinoid signaling has been shown to promote adult neurogenesis in the hippocampus and olfactory bulb (Takahashi et al, 1999; Thompson Haskell et al, 2002). In contrast, long-term administration of 13-cis-RA suppresses hippocampal neurogenesis and decreases hippocampal cell survival (Crandall et al, 2004). Reductions in hippocampal neurogenesis have been correlated with depression in human patients (Sheline et al, 1996; Bremner et al, 2000). In animal models, inescapable stress also reduces hippocampal neurogenesis, a phenomena that can be reversed with antidepressant treatment (Malberg and Duman, 2003). The ability of 13-cis-RA to increase depression-related behavior in the present study may be due to decreased hippocampal neurogenesis and cell survival and likely involves altered regulation of neuronal gene expression. Interestingly, adult neurogenesis requires functional serotonergic signaling (Brezun and Daszuta, 1999; Santarelli et al, 2003), further suggesting that 13-cis-RA mediates its effects by specifically regulating serotonergic gene expression and/or hippocampal neurogenesis.

13-Cis-RA is an effective treatment for severe recalcitrant acne (Shalita et al, 1988). However, 13-cis-RA use has been linked with depression, although this remains controversial (Jacobs et al, 2001; O'Connell et al, 2003; O'Donnell, 2003; Chai et al, 2005). Between 1982 and 2000, the US Food and Drug Administration received 431 reports of depression, suicidal ideation, suicidal attempts, and suicides in patients taking 13-cis-RA (Ng and Schweitzer, 2003). In addition, the Food and Drug Administration has received at least 24 case reports in which depression was resolved after 13-cis-RA use was discontinued, but recurred after drug rechallenge (Ault, 1998). Diagnosing depressive symptoms in acne patients following 13-cis-RA treatment is complicated by the psychological effects of severe acne itself. Clinically significant anxiety and depression symptoms have been reported in both adolescents and adults with chronic acne
(Koo, 1995; Kellett and Gawkrodger, 1999). Additionally, adolescents under social stress may be on the border of clinical depression and 13-cis-RA treatment may be a precipitating event (Gerard and Buehler, 2004). Despite the possible confounding effects of existing conditions, there are some instances where patients with no previous history of psychiatric symptoms develop depression and suicidal ideation following 13-cis-RA treatment (O'Donnell, 2003). Use of a mouse model allowed us to examine the effects of 13-cis-RA on depression-related behaviors exclusive of preexisting conditions, self-image, and other factors that confound human studies. This report is the first to demonstrate that 13-cis-RA administration enhances depression-related behaviors in mice. The mechanism by which this occurs is yet to be elucidated, although altered neuronal gene regulation and changes in hippocampal neurogenesis are likely to be involved.

\section{ACKNOWLEDGEMENTS}

We thank Dr Chris Bailey, Doug Barrett, and Elizabeth Johnson for technical assistance. We also like to thank Dr Yuri Blednov for the use of the rotarod. This research was supported by a University of Texas at Austin Fiscal Year Research Grant FY 2004-2005.

\section{REFERENCES}

Alcaro A, Cabib S, Ventura R, Puglisi-Allegra S (2002). Genotypeand experience dependent susceptibility to depressive-like responses in the forced-swimming test. Psychopharmacology (Berl) 164: 138-143.

Ault A (1998). Isotretinoin use may be linked with depression. Lancet 351: 730.

Axelson D, Birmaher B (2001). Relation between anxiety and depressive disorders in childhood and adolesence. Depress Anxiety 14: 67-78.

Barak Y, Wohl Y, Greenberg Y, Bar Dayan Y, Friedman T, Shoval G et al (2005). Affective psychosis following Accutane (isotretinoin) treatment. Int Clin Psychopharmacol 20: 39-41.

Bhatnagar S, Nowak N, Babich L, Bok L (2004). Deletion of the 5HT3 receptor differentially affects behavior of males and females in the Porsolt forced swim and defensive withdrawal tests. Behav Brain Res 153: 527-535.

Bigby M, Stern RS (1988). Adverse reactions to isotretinoin. A report from the Adverse Drug Reaction Reporting System. J Am Acad Dermatol 18: 543-552.

Bremner JD, Fani N, Ashraf A, Votaw JR, Brummer ME, Cummins $\mathrm{T}$ et al (2005). Functional brain imaging alterations in acne patients treated with isotretinoin. Am J Psychiatry 162: 983-991.

Bremner JD, Narayan M, Anderson E, Staib L, Miller H, Charney D (2000). Hippocampal volume reduction in major depression. Am J Psychiatry 157: 115-118.

Brezun J, Daszuta A (1999). Depletion in serotonin decreases neurogenesis in the dentate gyrus and subventricular zone of adult rats. J Neurosci 89: 999-1002.

Brooks SP, Pask T, Jones L, Dunnett SB (2004). Behavioural profiles of inbred mouse strains used as transgenic backgrounds. I: Motor tests. Genes Brain Behav 3: 206-215.

Byrne A, Hnatko G (1995). Depression associated with isotretinoin therapy. Can J Psychiatry 40: 567.

Carlezon Jr W, Pliakas A, Parow A, Detke M, Cohen B, Renshaw P (2002). Antidepressant like effects of cytidine in the forced swim test in rats. Biol Psychiatry 51: 882-889. 
Chai C, Lane W, Chibnall J, Allen A, Siegfried E (2005). Istoretinoin therapy and mood changes in adolescents with moderate to severe acne. Arch Dermatol 141: 557-560.

Charest A, Wainer BH, Albert PR (1993). Cloning and differentiation-induced expression of a murine serotonin1A receptor in a septal cell line. J Neurosci 13: 5164-5171.

Chiang MY, Misner D, Kempermann G, Schikorski T, Giguere V, Sucov HM et al (1998). An essential role for retinoid receptors RARbeta and RXRgamma in long-term potentiation and depression. Neuron 21: 1353-1361.

Cho S, Chung J, Han J, Ju Lee B, Han Kim D, Rhee K et al (2001a). 9-Cis-retinoic acid represses transcription of the gonadotropinreleasing hormone $(\mathrm{GnRH})$ gene via proximal promoter region that is distinct from all-trans-retinoic acid response element. Brain Res Mol Brain Res 87: 214-222.

Cho S, Chung JJ, Choe Y, Choi HS, Han Kim D, Rhee K et al (2001b). A functional retinoic acid response element (RARE) is present within the distal promoter of the rat gonadotropinreleasing hormone $(\mathrm{GnRH})$ gene. Brain Res Mol Brain Res 87: 204-213.

Cocco S, Diaz G, Stancampiano R, Diana A, Carta M, Curreli R et al (2002). Vitamin A deficiency produces spatial learning and memory impairment in rats. J Neurosci 115: 475-482.

Crandall J, Sakai Y, Zhang J, Koul O, Mineur Y, Crusio WE et al (2004). 13-Cis-retinoic acid suppresses hippocampal cell division and hippocampal-dependent learning in mice. Proc Natl Acad Sci USA 101: 5111-5116.

Cryan JF, Mombereau C, Vassout A (2005). The tail suspension test as a model for assessing antidepressant activity: review of pharmacological and genetic studies in mice. Neurosci Biobehav Rev 29: 571-625.

Cryan JF, Hoyer D, Markou A (2003). Withdrawl from chronic amphetamine induces depressive-like behavior in rodents. Biol Psychiatry 54: 49-58.

Dalla C, Antoniou K, Daifoti-Papadopoulou Z, Balthazart J, Bakker $\mathrm{J}$ (2004). Oestrogen deficient female aromatase knockout (ArKO) mice exhibit 'depressive-like' symptomology. Eur J Neurosci 20: 217-228.

Detke M, Rickels M, Lucki I (1995). Active behaviors in the rat forced swimming test differentially produced by serotonergic and noradrenergic antidepressants. Psychopharmacology 121: 66-72.

Do-Rego J, Chatenet D, Orta M, Naudin B, Le Cudennec C, Leprince $\mathrm{J}$ et al (2005). Behavioral effects of urotensin-II centrally administered in mice. Psychopharmacology (Berl) 14: $1-15$.

Ducottet C, Belzung C (2005). Correlations between behaviours in the elevated plus-maze and sensitivity to unpredictable subchronic mild stress: evidence from inbred strains of mice. Behav Brain Res 156: 153-162.

Dunn A, Swiergiel A (2005). Effects of interleukin-1 and endotoxin in the forced swim and tail suspension tests in mice. Pharmacol Biochem Behav 81: 688-693.

Eichele G (1997). Retinoids: from hindbrain patterning to Parkinson disease. Trends Genet 13: 343-345.

Etchamendy N, Enderlin V, Marighetto A, Pallet V, Higueret P, Jaffard R (2003). Vitamin A deficiency and relational memory deficit in adult mice: relationships with changes in brain retinoid signalling. Behav Brain Res 145: 37-49.

Etchamendy N, Enderlin V, Marighetto A, Vouimba RM, Pallet V, Jaffard $\mathrm{R}$ et al (2001). Alleviation of a selective age-related relational memory deficit in mice by pharmacologically induced normalization of brain retinoid signaling. J Neurosci 21: 64236429.

Ferahbas A, Turan MT, Esel E, Utas S, Kutlugun C, Kilic CG (2004). A pilot study evaluating anxiety and depressive scores in acne patients treated with isotretinoin. J Dermatol Treat 15: 153-157.
Ferguson S, Cisneros F, Gough B, Hanig J, Berry K (2005). Chronic oral treatment with 13-cis-retinoic acid (isotretinoin) or alltrans-retinoic acid does not alter depression-like behaviors in rats. Toxicol Sci 87: 451-459.

Gerard JM, Buehler C (2004). Cumulative environmental risk and youth maladjustment: the role of youth attributes. Child Dev 75: $1832-1849$.

Hazen PG, Carney JF, Walker AE, Stewart JJ (1983). Depression - a side effect of 13-cis-retinoic acid therapy. J Am Acad Derm 9: 278-279.

Hull PR, D'Arcy C (2003). Isotretinoin use and subsequent depression and suicide. Am J Clin Derm 4: 493-505.

Husson M, Enderlin V, Alfos S, Boucheron C, Pallet V, Higueret P (2004). Expression of neurogranin and neuromodulin is affected in the striatum of vitamin A-deprived rats. Brain Res Mol Brain Res 123: 7-17.

Idres N, Marill J, Flexor MA, Chabot GG (2002). Activation of retinoic acid receptor-dependent transcription by all-transretinoic acid metabolites and isomers. J Biol Chem 277: 3149131498.

Iniguez MA, Morte B, Rodriguez-Pena A, Munoz A, Gerendasy D, Sutcliffe JG et al (1994). Characterization of the promoter region and flanking sequences of the neuron-specific gene RC3 (neurogranin). Brain Res Mol Brain Res 27: 205-214.

Jacobs BL, van Praag H, Gage FH (2000). Adult brain neurogenesis and psychiatry: a novel theory of depression. Mol Psychiatry 5: 262-269.

Jacobs DG, Deutsch NL, Brewer M (2001). Suicide, depression, and isotretinoin: is there a causal link? J Am Acad Dermatol 45: S168-S175.

Jick SS, Kremers HM, Vasilakis-Scaramozza C (2000). Isotretinoic use and risk of depression, psychotic symptoms, suicide, and attempted suicide. Arch Dermatol 136: 1231-1236.

Kellett SC, Gawkrodger DJ (1999). The psychological and emotional impact of acne and the effect of treatment with isotretinoin. $\mathrm{Br} J$ Dermatol 140: 273-282.

Kerr IG, Lippman ME, Jenkins J, Myers CE (1982). Pharmacology of 13-cis-retinoic acid in humans. Cancer Res 42: 2069-2073.

Klimek V, Schenck JE, Han H, Stockmeier CA, Ordway GA (2002). Dopaminergic abnormalities in amygdaloid nuclei in major depression: a postmortem study. Biol Psychiatry 52: 740-748.

Koo J (1995). The psychosocial impact of acne: patients' perceptions. J Am Acad Dermatol 32: S26-S30.

Krezel W, Ghyselinck N, Samad TA, Dupe V, Kastner P, Borrelli E et al (1998). Impaired locomotion and dopamine signaling in retinoid receptor mutant mice. Science 279: 863-867.

Krezel W, Kastner P, Chambon P (1999). Differential expression of retinoid receptors in the adult mouse central nervous system. J Neurosci 89: 1291-1300.

Lane MA, Bailey SJ (2005). Role of retinoid signalling in the adult brain. Prog Neurobiol 72: 275-293.

Lane MA, Chen AC, Roman SD, Derguini F, Gudas LJ (1999). Removal of LIF (leukemia inhibitory factor) results in increased vitamin A (retinol) metabolism to 4-oxoretinol in embryonic stem cells. Proc Natl Acad Sci USA 96: 1352413529.

Lucki I (1997). The forced swimming test as a model for core and component behavioral effects of antidepressant drugs. Behav Pharmacol 8: 523-532.

Lucki I, Dalvi A, Mayorga AJ (2001). Sensitivity to the effects of pharmacologically selective antidepressants in different strains of mice. Psychopharmacology 155: 315-322.

Luthi-Carter R, Strand A, Peters N, Solano S, Hollingsworth Z, Menon A et al (2000). Decreased expression of striatal signaling genes in a mouse model of Huntington's diseas. Hum Mol Genet 9: $1259-1271$.

Maden M (2002). Retinoid signalling in the development of the central nervous system. Nat Rev Neurosci 3: 843-853. 
Malberg JE, Duman R (2003). Cell proliferation in adult hippocampus is decreased by inescable stress: reversal by fluoxetine treatment. Neuropsychopharmacology 28: 1562-1571.

Malberg JE, Schechter LE (2005). Increasing hippocampal neurogenesis: a novel mechanism for antidepressant drugs. Curr Pharm Design 11: 145-155.

Mathis C, Paul SM, Crawley JN (1994). Characterization of benzodiazepine-sensitive behaviors in the $\mathrm{A} / \mathrm{J}$ and $\mathrm{C} 57 \mathrm{BL} / 6 \mathrm{~J}$ inbred strains of mice. Behav Genet 24: 171-180.

McCaffery PJ, Drager UC (1994). High levels of a retinoic acidgenerating dehydrogenase in the meso-telencephalic dopamine system. Proc Natl Acad Sci USA 91: 7772-7776.

Mey J, McCaffery P (2004). Retinoic acid signaling in the nervous system of adult vertebrates. Neuroscientist 10: 409-421.

$\mathrm{Ng} \mathrm{CH}$, Schweitzer I (2003). The association between depression and isotretinoin use in acne. Aust N Z J Psychiatry 37: 78-84.

O'Connell KA, Wilkin JK, Pitts M (2003). Isotretinoin (Accutane) and serious psychiatric adverse events. J Am Acad Dermatol 48: 306-308.

O’Donnell J (2003). Overview of existing research and information linking isotretinoin (accutane), depression, psychosis, and suicide. Am J Ther 10: 148-159.

Prut L, Belzung C (2003). The open field as a paradigm to measure the effects of drugs on anxiety-like behaviors: a review. Eur J Pharmacol 463: 3-33.

Richard S, Zingg HH (1991). Identification of a retinoic acid response element in the human oxytocin promoter. J Biol Chem 266: 21428-21433.

Samad TA, Krezel W, Chambon P, Borrelli E (1997). Regulation of dopaminergic pathways by retinoids: activation of the D2 receptor promoter by members of the retinoic acid receptor-retinoid X receptor family. Proc Natl Acad Sci USA 94: 14349-14354.

Santarelli L, Saxe M, Gross C, Surget A, Battaglia F, Dulawa S et al (2003). Requirement of hippocampal neurogenesis for the behavioral effects of antidepressants. Science 301: 805-809.

Scheinman PL, Peck GL, Rubinow DR, DiGiovanna JJ, Abangan DL, Ravin PD (1990). Acute depression from isotretinoin. J Am Acad Dermatol 22: 1112-1114.

Shalita AR, Armstrong RB, Leyden JJ, Pochi PE, Strauss JS (1988). Isotretinoin revisited. Cutis 42: 1-19.

Sheline Y, Wang P, Gado M, Csernansky J, Vannier M (1996). Hippocampal atrophy in recurrent major depression. Proc Natl Acad Sci USA 93: 3908-3913.

Shumake J, Barrett D, Gonzalez-Lima F (2005). Behavioral characteristics of rats predisposed to learned helplessness: reduced reward sensitivity, increased novelty seeking, and persistent fear memories. Behav Brain Res 164: 222-230.

Shumake J, Gonzalez-Lima F (2003). Brain systems underlying susceptibility to helplessness and depression. Behav Cogn Neurosci Rev 2: 198-221.

Singewald N, Sinner C, Hetzenauer A, Sartori S, Murck H (2004). Magnesium-deficient diet alters depression- and anxiety-related behavior in mice-influence of desipramine and Hypercium perforatum extract. Neuropharmacology 47: 11891197.

Strobel A, Gutknecht L, Rothe C, Reif A, Mossner R, Zeng Y et al (2003). Allelic variation in 5-HT1A receptor expression is associated with anxiety- and depression-related personality traits. J Neural Transm 110: 1445-1453.

Takahashi J, Palmer TD, Gage FH (1999). Retinoic acid and neurotrophins collaborate to regulate neurogenesis in adultderived neural stem cell cultures. J Neurobiol 38: 65-81.

Thompson Haskell G, Maynard TM, Shatzmiller RA, Lamantia AS (2002). Retinoic acid signaling at sites of plasticity in the mature central nervous system. J Comp Neurol 452: 228-241.

Tsukada M, Schroder M, Roos TC, Chandraratna RAS, Reichert U, Mark HF et al (2000). 13-Cis-retinoic acid exerts its specific activity on human sebocytes through selective intracellular isomerization to all-trans retinoic acid and binding to retinoic acid receptors. J Invest Dermatol 115: 321-327.

Valdenaire O, Maus-Moatti M, Vincent JD, Mallet J, Vernier P (1998). Retinoic acid regulates the developmental expression of dopamine D2 receptor in rat striatal primary cultures. J Neurochem 71: 929-936.

Valdenaire O, Vernier P, Maus M, Dumas Milne Edwards JB, Mallet J (1994). Transcription of the rat dopamine-D2-receptor gene from two promoters. Eur J Biochem 220: 577-584.

Wagner E, Luo T, Drager UC (2002). Retinoic acid synthesis in the postnatal mouse brain marks distinct developmental stages and functional systems. Cereb Cortex 12: 1244-1253.

Wysowski DK, Pitts M, Beitz J (2001). Depression and suicide in patients treated with isotretinoin. N Engl J Med 344: 460.

Zetterstrom RH, Lindqvist E, Mata de Urquiza A, Tomac A, Eriksson U, Perlmann T et al (1999). Role of retinoids in the CNS: differential expression of retinoid binding proteins and receptors and evidence for presence of retinoic acid. Eur $J$ Neurosci 11: 407-416.

Zetterstrom RH, Simon A, Giacobini MM, Eriksson U, Olson L (1994). Localization of cellular retinoid-binding proteins suggests specific roles for retinoids in the adult central nervous system. J Neurosci 62: 899-918. 